\title{
Multilayered Electrochromic Films of Metal Hexacyanoferrates Nanoparticles
}

\author{
Hisashi Tanaka ${ }^{1}$,Hiroshi Watanabe ${ }^{1}$, Masato Kurihara ${ }^{2}$, and Tohru Kawamoto ${ }^{1 *}$ \\ ${ }^{1}$ Nanomaterials Research Institute, National Institute of Advanced Industrial Science and Technology, \\ 1-1-1 Higashi, Tsukuba, Ibaraki 305-8565, Japan. \\ ${ }^{2}$ Department of Biological Chemistry, Faculty of Science, Yamagata University, 1-4-12 Kojirakawa- \\ machi, Yamagata, Yamagata 990-8560, Japan \\ "E-mail: tohru.kawamoto@aist.go.jp; ORCID: orcid.org/0000-0002-3984-2980
}

doi: $10.20964 / 2018.05 .78$

Received: 9 December 2017 / Accepted: 16 February 2018 / Published: 10 April 2018

\begin{abstract}
Multi-layered thin films exhibiting electrochromism have been developed using sequential coating processes with water-dispersible nanoparticles of metal $(\mathrm{Fe}, \mathrm{Ni})$ hexacyanoferrates. To fabricate the multi-layered films, a simple method is developed to avoid re-dispersion of the water-dispersible film using a dip-washing process in aqueous solutions of metallic salt. On the one hand, the thickness of the multi-coated film of the nanoparticles of iron hexacyanoferrate (FeHCF: Prussian blue) is estimated to be $100 \mathrm{~nm}, 190 \mathrm{~nm}, 300 \mathrm{~nm}$, and $420 \mathrm{~nm}$ for single, double, triple, and quadruple layers, respectively, and the optical absorbance of the multi-coated film shows dense color proportional to the number of coatings. On the other hand, the double-layered film composed of FeHCF and nickel hexacyanoferrate (NiHCF) layers of thicknesses estimated to be $110 \mathrm{~nm}$ and $840 \mathrm{~nm}$, respectively, shows electrochromism among green, blue, and colorless, where green is the blend of the colors of FeHCF and NiHCF.
\end{abstract}

Keywords: electrochromism, Prussian blue, metal hexacyanoferrate, nanoparticle, multilayered film, spin-coating

\section{FULL TEXT}

(C) 2018 The Authors. Published by ESG (www.electrochemsci.org). This article is an open access article distributed under the terms and conditions of the Creative Commons Attribution license (http://creativecommons.org/licenses/by/4.0/). 